\title{
Supplementary Materials for "Air quality during COVID-19 lockdown in the Yangtze River Delta and the Pearl River Delta: two different responsive mechanisms to emission reductions in China"
}

Nan Wang ${ }^{1,2,3}$, Jiawei $\mathrm{Xu}^{1,3}$, Chenglei Pei ${ }^{4}$, Rong Tang ${ }^{1,3}$, Derong Zhou ${ }^{1,3}$, Yanning

Chen $^{4}$, Mei Li ${ }^{5,6}$, Xuejiao Deng ${ }^{2}$, Tao Deng ${ }^{2}$, Xin Huang ${ }^{1,3 *}$, Aijun Ding ${ }^{1,3}$

${ }^{1}$ Joint International Research Laboratory of Atmospheric and Earth System Sciences, School of Atmospheric Sciences, Nanjing University, Nanjing, China

${ }^{2}$ Institute of Tropical and Marine Meteorology/Guangdong Provincial Key Laboratory of Regional Numerical Weather Prediction, China Meteorological Administration, Guangzhou, China

3 Jiangsu Provincial Collaborative Innovation Center for Climate Change, Nanjing, China

${ }^{4}$ Guangzhou Environmental Monitoring Center, Guangzhou, China

${ }^{5}$ Institute of Mass Spectrometer and Atmospheric Environment, Guangdong Provincial Engineering Research Center for On-Line Source Apportionment System of Air Pollution, Jinan University Guangzhou, China

${ }^{6}$ Guangdong-Hong Kong-Macau Joint Laboratory of Collaborative Innovation for Environmental Quality Guangzhou, China 


\section{Supporting Information}

Supportin Information includes 7 pages, 2 text, 6 figures and 3tables

Text S1. Section 1. WRF-Chem emissions and scenario setting, $p 3$

Text S2. Section 2. Section 2. Spatial distribution of O3-NOx-VOCs sensitivities.

,$p 4$

SI Figures S1-S6, p5-p7

SI Tables S1-S3, $p 8$

SI References, $p 9$ 


\section{Section 1. WRF-Chem emissions and scenario setting}

In this work, air quality was simulated with WRF-Chem model based on two sets of emission inventories, i.e., a business as usual emission inventory (BAU EI) and an upto-date emissions inventory (COVID-19 EI), and two sets of meteorological conditions, i.e., the PRE meteorology and the LOCK meteorology, respectively. The PRE meteorology and LOCK meteorology represent the real weather conditions during the PRE period and the LOCK period, respectively. The BAU EI represents no control throughout the whole period which is directly obtained from the bottom-up inventory, Model of Multi resolution Emission Inventory for China (MEIC). MEIC, with a grid resolution of $0.25^{\circ} \times 0.25^{\circ}$, was developed by Tsinghua University ${ }^{1}$ and has been updating monthly anthropogenic emissions (like $\mathrm{SO}_{2}, \mathrm{NO}_{2}, \mathrm{CO}, \mathrm{PM}, \mathrm{NMVOCs}$ and so on) since the year of 2008. The COVID-19 EI represent the situation of the COVID-19 lockdown And was calculated based on a set of dynamic data. For the sector of power, emissions were adjusted based on the variation rate of the thermal power generation data (obtained from National Bureau of Statistics, http://www.stats.gov.cn). The statistics witnessed $8.9 \%$ decreased in the first two months of 2020 than that in 2019, whereas the data in 2019 was $1.7 \%$ more than in 2018, the difference in the growth rates between 2019 and 2020 was regarded as the influence of COVID-19 lockdown on the power sector emissions. Similarly, cement emissions were then estimated to be reduced by $30 \%$ with the considering of the production rate. For the residential sector, emissions from the commercial use of boilers and stoves in the urban region were eliminated due to the COVID-shutdown, while emissions from residential heating and cooking in both urban and rural areas were assumed not affected. Emissions from transportation were estimated to be reduced by $70 \%$ according to the transportation index data. As a result, anthropogenic emissions of CO, NOx, SO2, VOCs, PM2.5, BC and OC were reduced by 35\%, 48\%, 42\%, 45\%, 34\%, 54\% and $42 \%$ in Shanghai, $23 \%$, $50 \%, 26 \%, 41 \%, 16 \%, 35 \%$, and $7 \%$ in Jiangsu, $41 \%, 50 \%, 29 \%, 45 \%, 30 \%, 49 \%$ and $20 \%$ in Zhejiang, and 38\%, 50\%, 33\%, 46\%, 27\%, 42\% and 13\% in Guangdong, respectively. Detailed information was provided in our previous paper ${ }^{2}$.Apart from anthropogenic emissions, natural emissions were online calculated with the incorporated MEGAN module (Model of Emissions of Gases and Aerosols from Nature) in WRF-Chem.

To investigate the effects of emission reductions and meteorological conditions on air quality, three scenarios were proposed ( $\mathrm{S} 0, \mathrm{~S} 1$ and $\mathrm{S} 2$ ). S0 covers the period of the PRE using the BAU EI and driven by the PRE meteorology, representing the real condition before the COVID-19 lockdown. S1 covers the period of the LOCK using BAU EI and driven by the LOCK meteorology, this is an assumed scenario that supposing there is no COVID-19 lockdown. S2 covers the period of the LOCK using the COVID-19 EI and the LOCK meteorology, representing the real situation during the LOCK. The difference between S1 and S0 provides us the impact of meteorology. The difference between S2 and S1 provides us the impact of emission control. And the absolute ratio of (S1-S0)/(S2-S1) represents the weight between meteorology impact and emission reduction impact. 


\section{Section 2. Spatial distribution of O3-NOx-VOCs sensitivities.}

In order to understand the responses of $\mathrm{O}_{3}$ to its precursors, the $\mathrm{O}_{3}$-NOx-VOCs sensitivities were explored by using two methods. One is indicated by the ratios of $\mathrm{HCHO} / \mathrm{NO}_{2}$, derived from satellite retrievals. The other is indicated by the ratio of $\mathrm{P}\left(\mathrm{H}_{2} \mathrm{O}_{2}\right) / \mathrm{P}\left(\mathrm{HNO}_{3}\right)$, acquired from WRF-Chem simulations. In this study, the $\mathrm{HCHO} / \mathrm{NO}_{2}$ ratio below 1 was considered as NOx-saturated (VOCs-limited) regime; the $\mathrm{HCHO} / \mathrm{NO}_{2}$ ratio above 2 reflected the $\mathrm{NOx}$-limited regime; and the $\mathrm{HCHO} / \mathrm{NO}_{2}$ ratio between 1 and 2 indicated the mixed-limited regime ${ }^{3}$. Similarly, the $\mathrm{P}\left(\mathrm{H}_{2} \mathrm{O}_{2}\right) / \mathrm{P}\left(\mathrm{HNO}_{3}\right)$ ratio below 0.35 was considered as NOx-saturated (VOCs-limited) regime; the $\mathrm{P}\left(\mathrm{H}_{2} \mathrm{O}_{2}\right) / \mathrm{P}\left(\mathrm{HNO}_{3}\right)$ ratio above 0.60 reflected the NOx-limited regime; and the $\mathrm{P}\left(\mathrm{H}_{2} \mathrm{O}_{2}\right) / \mathrm{P}\left(\mathrm{HNO}_{3}\right)$ ratio between 0.35 and 0.60 indicated the mixed-limited regime ${ }^{4,5}$.

It should be noted that both methods had uncertainties, the satellite-derived products were affected by clouds, aerosols, precipitations, and surface reflectivity since they were based on optical principle. Meanwhile, the satellite observations provided only column concentrations (different to the ground-level concentrations) and were limited to the satellite passing time. On the other hand, $\mathrm{P}\left(\mathrm{H}_{2} \mathrm{O}_{2}\right) / \mathrm{P}\left(\mathrm{HNO}_{3}\right)$, obtained from WRFChem results, was also affected by the uncertainties by numerical simulations, such as the uncertainty from emission inventories and the accuracy from meteorological simulations. Figure $\mathrm{S} 4$ shows the distribution of $\mathrm{O}_{3}-\mathrm{NOx}-\mathrm{VOCs}$ sensitivities by these two methods, the general patterns were reasonably well matched. 

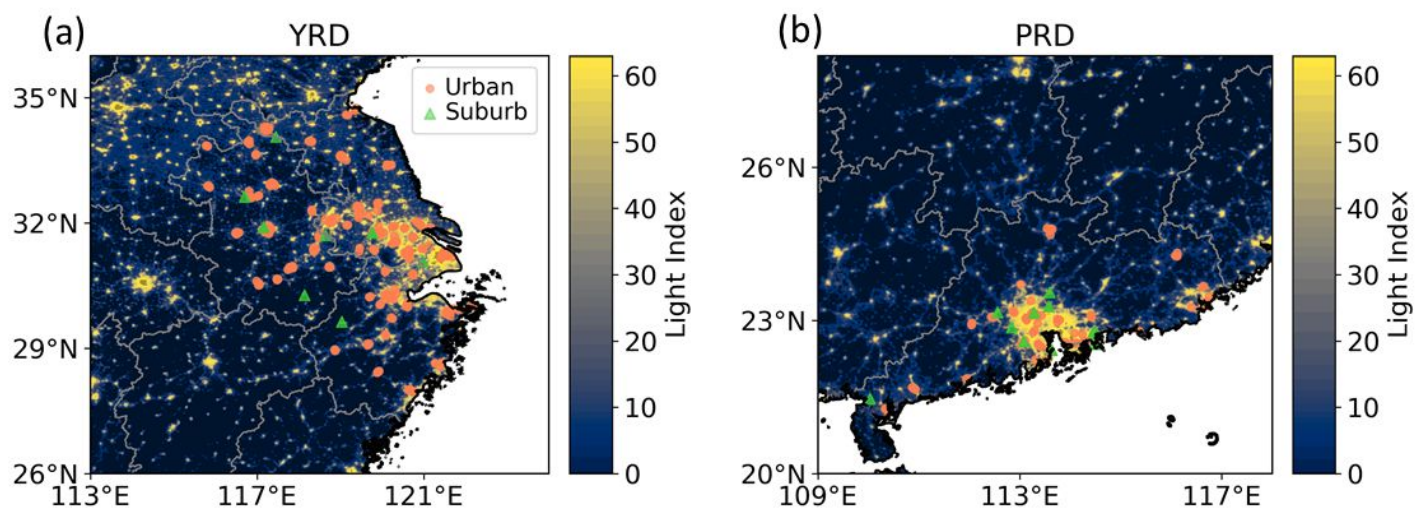

Figure S1. Spatial distribution of nighttime light index (contoured) and the locations of urban and suburb monitoring sites (scattered).
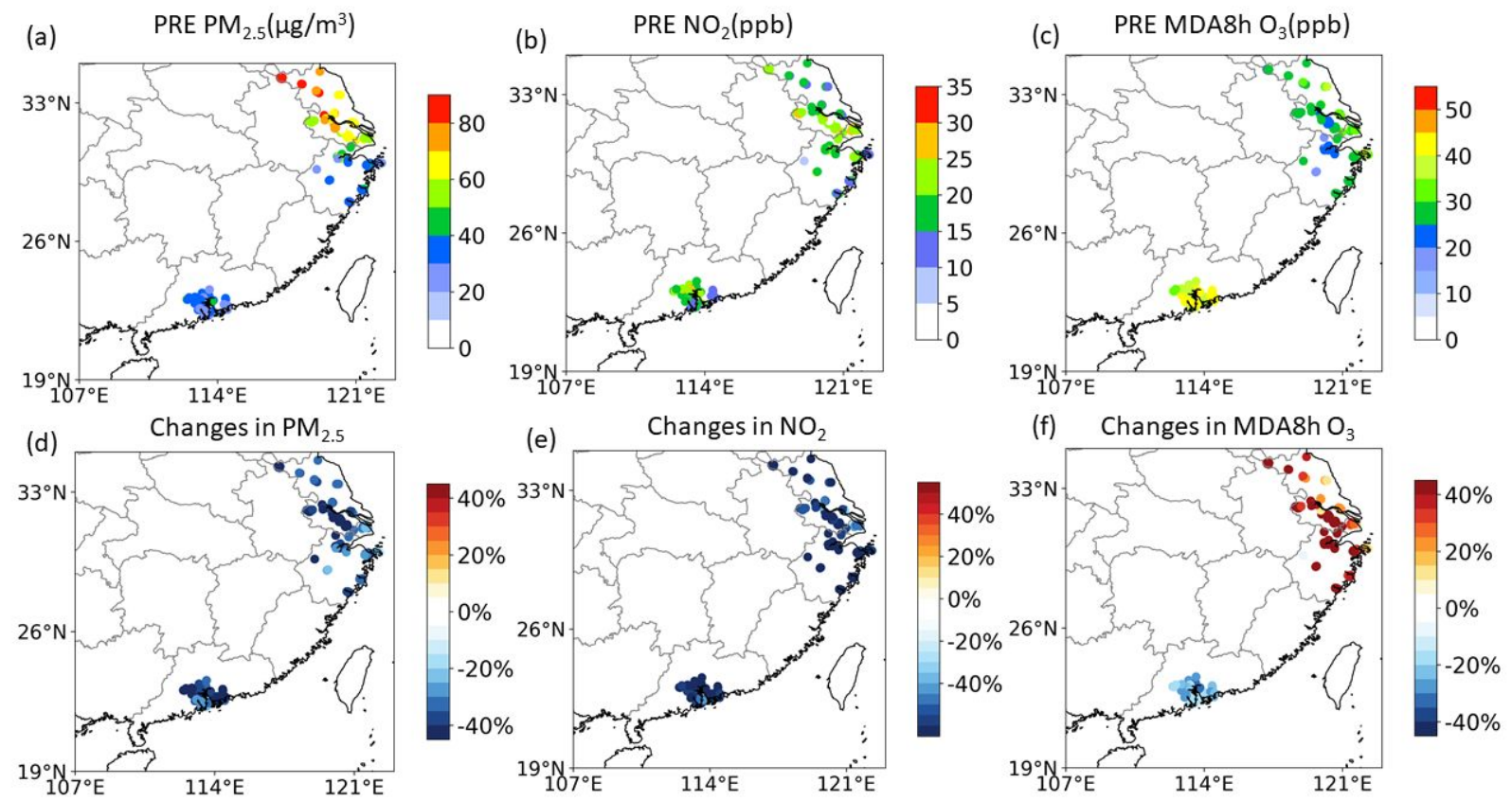

Figure S2 (a-c) Spatial distribution of averaged $\mathrm{PM}_{2.5}, \mathrm{NO}_{2}$ and $\mathrm{O}_{3} \mathrm{MDA} 8 \mathrm{~h}$ $\left(\mathrm{O}_{3} \mathrm{MDA} 8 \mathrm{~h}\right.$ refers to maxima of $8 \mathrm{~h} \mathrm{O}_{3}$ concentrations of a day) during the PRE period. (d-f) Spatial changes of $\mathrm{PM}_{2.5}, \mathrm{NO}_{2}$ and $\mathrm{O}_{3} \mathrm{MDA} 8 \mathrm{~h}$ between LOCK and PRE 

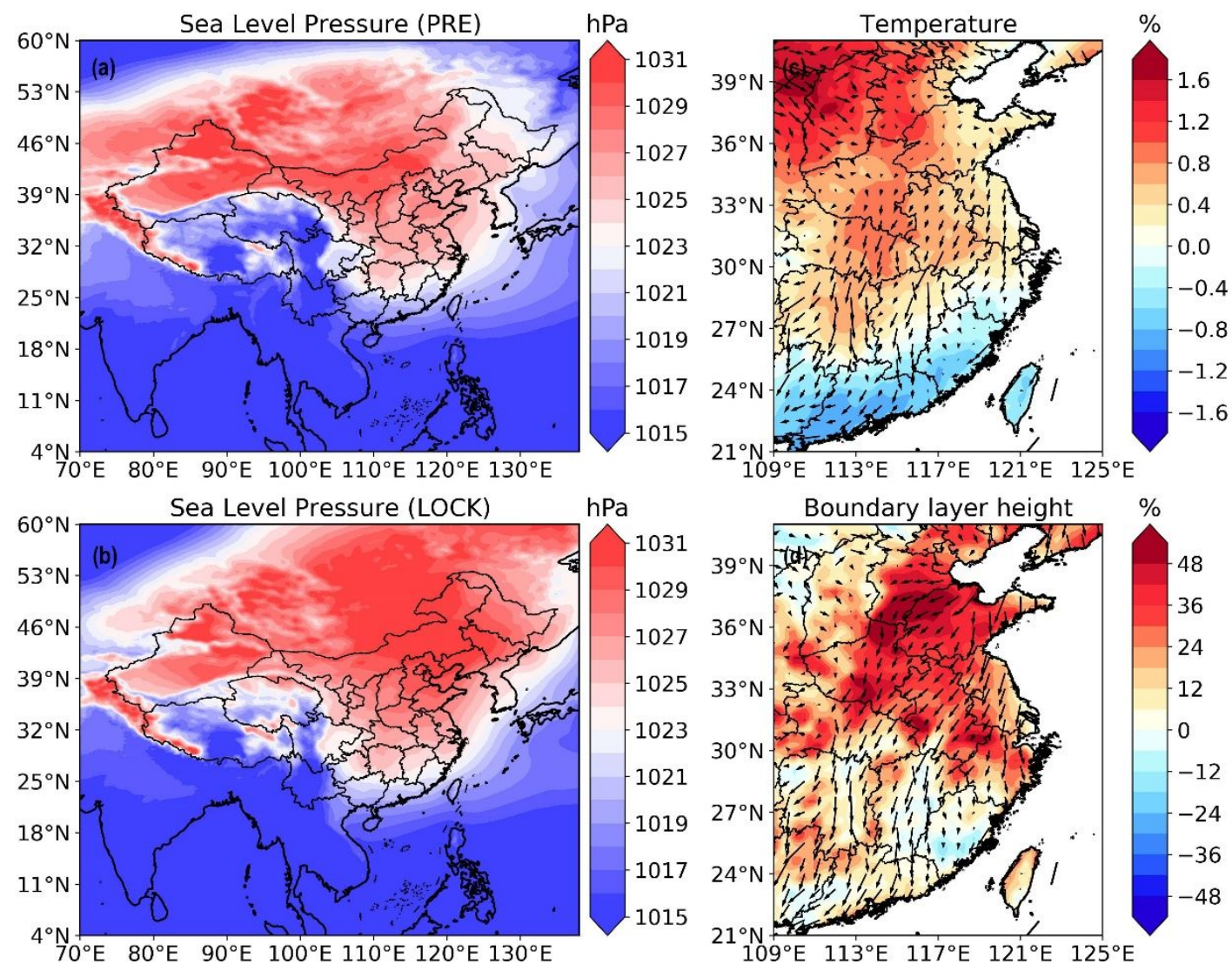

Figure S3 (a) Averaged sea level pressure based on ERA5 reanalysis data in the PRE period. (b) Same as (a) but in the LOCK period. (c) Averaged changes of surfaces temperature between the PRE and the LOCK with averaged synoptic winds of the PRE. (d) Same as (c) but for changes in boundary layer height with averaged synoptic winds of the LOCK.

(a)

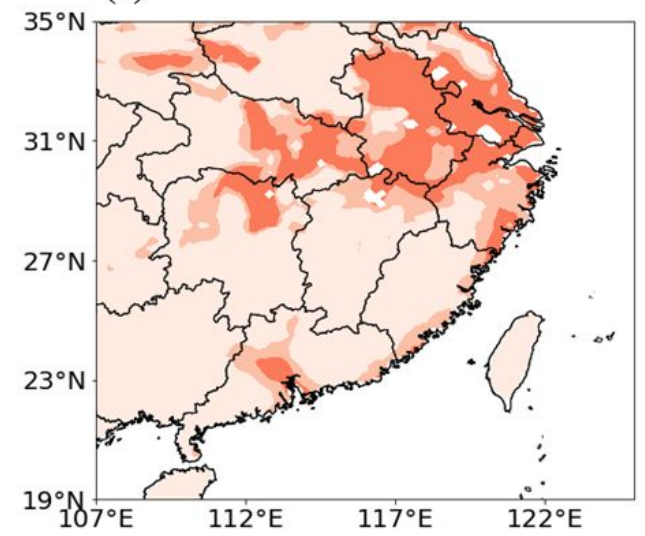

(b)

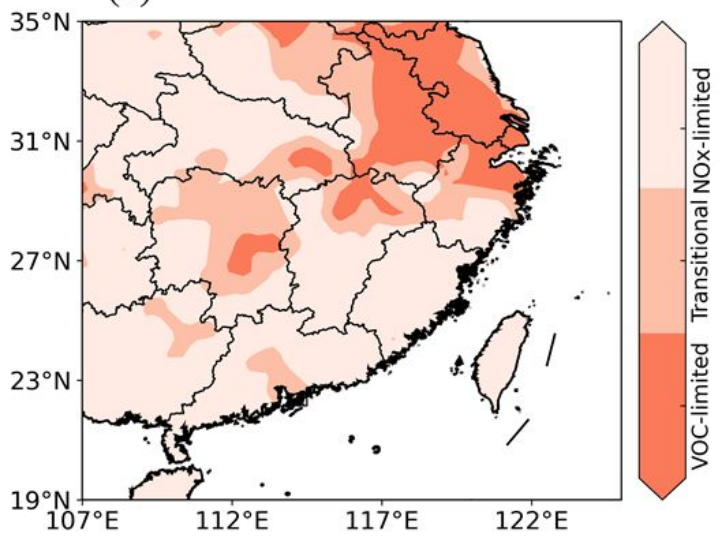

Figure S4. (a) WRF-Chem simulated $\mathrm{O}_{3}$-VOCs-NOx sensitive regime based on the ratio of $\mathrm{P}_{\mathrm{H} 2 \mathrm{O} 2} / \mathrm{P}_{\mathrm{HNO} 3}$. (b) Satellite-based diagnosed $\mathrm{O}_{3}$-VOCs-NOx sensitive regime based on the ratio of $\mathrm{HCHO} / \mathrm{NO}_{2}$. 

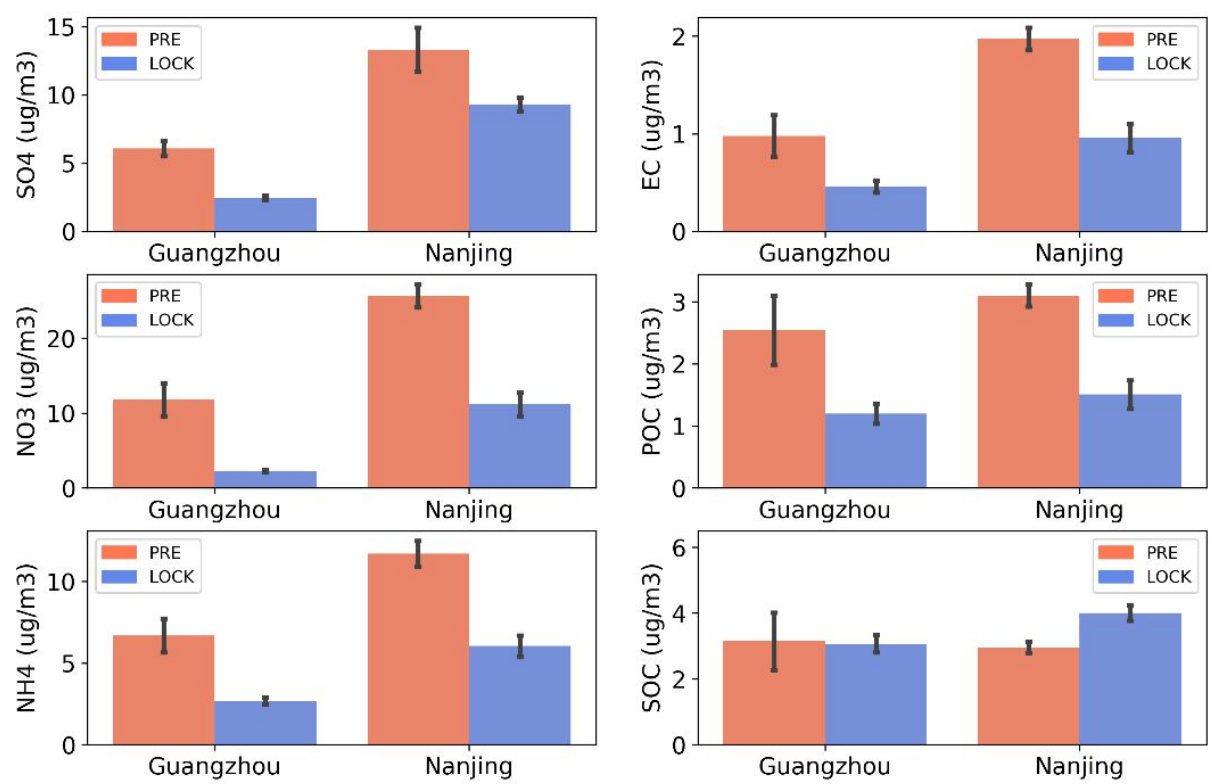

Figure S5. Comparison $\mathrm{PM}_{2.5}$ components during PRE and LOCK period in Guangzhou and Nanjing
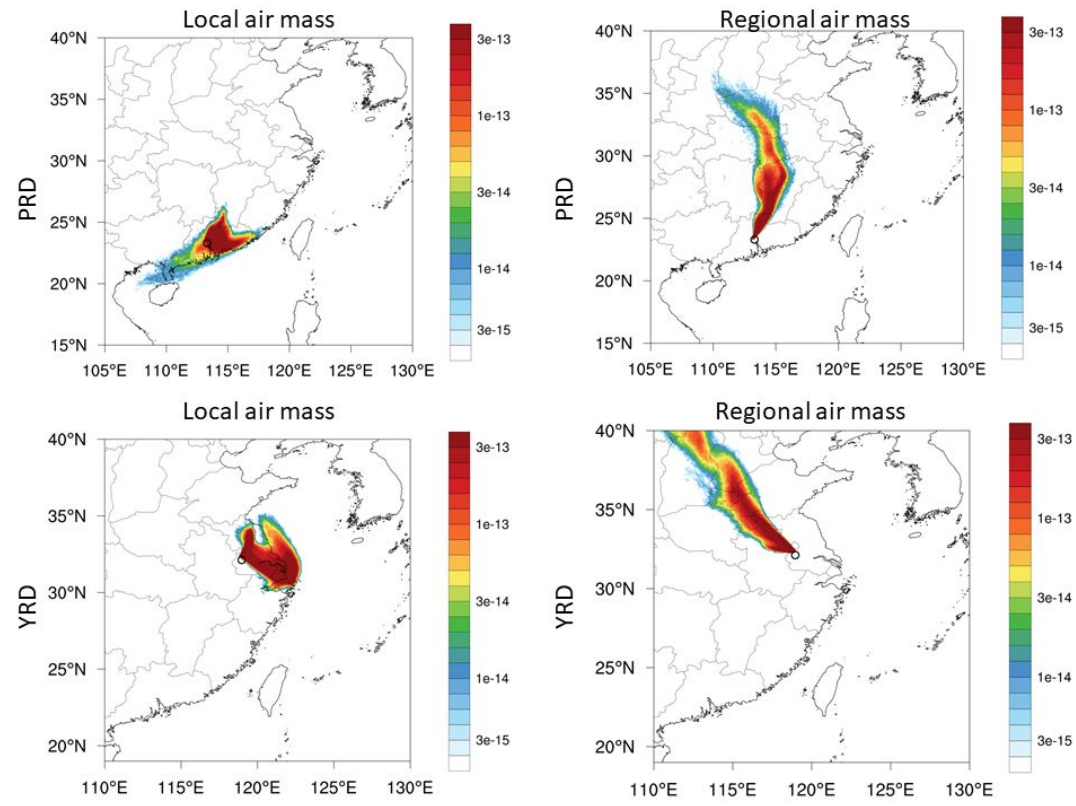

Figure S6. Classification of air flow based on LPDM calculated retroplumes in PRD and YRD, respectively. 
Table S1 Introduction of monitoring instruments used in this work

\begin{tabular}{|c|c|c|c|c|c|}
\hline \multirow{2}{*}{$\frac{\text { Parameter }}{\mathrm{O} 3}$} & \multicolumn{3}{|c|}{ Manufacture } & \multirow{2}{*}{$\frac{\text { model }}{\text { TEI-49i }}$} & \multirow{2}{*}{$\frac{\text { resolution }}{5 \mathrm{~min}}$} \\
\hline & $\begin{array}{l}\text { Thermo } \\
\text { USA }\end{array}$ & Fisher & Scientific, & & \\
\hline $\mathrm{CO}$ & $\begin{array}{l}\text { Thermo } \\
\text { USA }\end{array}$ & Fisher & Scientific, & TEI-48i & $5 \mathrm{~min}$ \\
\hline PM2.5 & $\begin{array}{l}\text { Thermo } \\
\text { USA }\end{array}$ & Fisher & Scientific, & TEI 42i & $5 \mathrm{~min}$ \\
\hline $\mathrm{OC} 、 \mathrm{EC}$ & Sunset L & iboratory & Inc., USA & RT-4 & $1 \mathrm{~h}$ \\
\hline SNA(sulfate, nitrate, ammonium) & Metrohm & Switzer & land & MARGA & $1 \mathrm{~h}$ \\
\hline
\end{tabular}

Table S2 Configuration of WRF-Chem model

\begin{tabular}{ll}
\hline Item & Domain 1 \\
\hline Horizontal grid & 161,181 \\
Vertical layers & 30 \\
Grid spacing & $20 \times 20 \mathrm{~km}$ \\
Microphysics & Lin et al. \\
Short-wave radiation & RRTMG \\
Long-wave radiation & RRTMG \\
Surface layer & Monin-Obukhov \\
Land-surface model & Noah \\
Boundary layer & YSU \\
Cumulus parameterization & Grell-Devenyi ensemble scheme \\
Biogenic emission & MEGAN online calculation \\
Chemistry option & CBMZ \\
Aerosol option & MOSAIC \\
\hline
\end{tabular}

Table S3 Averaged model performance of $\mathrm{O}_{3}, \mathrm{NO}_{2}$ and $\mathrm{O}_{3}$ in $\mathrm{YRD}^{\mathrm{a}}$ and $\mathrm{PRD}^{\mathrm{b}}$

\begin{tabular}{ccccccc}
\hline \multirow{2}{*}{$\begin{array}{c}\text { Simulated } \\
\text { variables }\end{array}$} & \multicolumn{2}{c}{$\mathrm{O}_{3}$} & \multicolumn{2}{c}{$\mathrm{NO}_{2}$} & \multicolumn{2}{c}{$\mathrm{PM}_{2.5}$} \\
\cline { 2 - 7 } & YRD & PRD & YRD & PRD & YRD & PRD \\
\hline $\mathrm{NME}^{\mathrm{c}}$ & 0.45 & 0.33 & 0.54 & 0.56 & 0.38 & 0.52 \\
$\mathrm{NMB}^{\mathrm{d}}$ & 0.02 & 0.16 & 0.46 & 0.15 & -0.24 & 0.04 \\
$\mathrm{RMSE}^{\mathrm{e}}$ & 9.43 & 9.28 & 30.6 & 25.95 & 10.3 & 24.7 \\
$\mathrm{IOA}^{\mathrm{f}}$ & 0.71 & 0.69 & 0.77 & 0.67 & 0.75 & 0.61 \\
\hline
\end{tabular}

YRD ${ }^{\mathrm{a}}$ : There are 42 monitoring sites in YRD used for model evaluation; $\mathrm{PRD}^{\mathrm{a}}$ : There are 40 monitoring sites in PRD used for model evaluation; $\mathrm{NME}^{\mathrm{C}}$ : normal mean error; $\mathrm{NMB}^{\mathrm{d}}$ : normal mean bias; $\mathrm{RMSE}^{\mathrm{e}}$ : root mean square error; $\mathrm{IOA}^{\mathrm{f}}$ : the index of agreement. 


\section{SI Reference}

1. Li, M.; Zhang, Q.; Streets, D.; He, K.; Cheng, Y.; Emmons, L.; Huo, H.; Kang, S.; Lu, Z.; Shao, M., Mapping Asian anthropogenic emissions of non-methane volatile organic compounds to multiple chemical mechanisms. Atmospheric Chemistry and Physics 2014, 14, (11), 5617-5638.

2. HuangXin, Enhanced secondary pollution offset reduction of primary emissions during COVID-19 lockdown in China. 2020.

3. Jin, X.; Holloway, T., Spatial and temporal variability of ozone sensitivity over China observed from the Ozone Monitoring Instrument. Journal of Geophysical Research: Atmospheres 2015, 120, (14), 7229-7246.

4. Wang, N.; Lyu, X.; Deng, X.; Huang, X.; Jiang, F.; Ding, A., Aggravating O3 pollution due to NOx emission control in eastern China. The Science of the total environment 2019, 677, 732-744.

5. $\quad$ Wang, N.; Lyu, X. P.; Deng, X. J.; Guo, H.; Deng, T.; Li, Y.; Yin, C. Q.; Li, F.; Wang, S. Q., Assessment of regional air quality resulting from emission control in the Pearl River Delta region, southern China. The Science of the total environment 2016, 573, 1554-1565. 